\title{
Continuous assessment of labour pain using handgrip force
}

\author{
Nadine Wickboldt $M D^{1,2}$, Georges Savoldelli MD², Benno Rehberg-Klug MD²
}

N Wickboldt, G Savoldelli, B Rehberg-Klug. Continuous assessment of labour pain using handgrip force. Pain Res Manag 2015;20(3):159-163.

BACKGROUND: Assessment of dynamic changes in painful experiences, such as labour, using conventional rating scales (eg, numerical rating scale [NRS]) has limitations. An alternative for continuous pain evaluation could be a signal generated by voluntary action of the parturient. Remifentanil administration for obstetric analgesia could be improved by these dynamic measures of labour pain. In the present study, handgrip force was measured by a dynamometer to signal labour pain.

OBJECTIVES: To evaluate: whether continuous monitoring of labour pain using handgrip force allows for determination of pain measurement during contractions; and the correlation between handgrip force and pain intensity on NRS.

METHODS: The present observational, single-centre study included 43 parturients. After calibration of the dynamometer for individual hand muscle strength, pain was recorded during early and late labour using a dynamometer and an NRS. The primary end point was the correlation coefficient between NRS ratings and peak intensity recorded by the dynamometer.

RESULTS: All dynamometer-registered readings were also registered by the external tocogram. All contractions recorded by external tocogram were also registered by the dynamometer. Handgrip force was moderately correlated with pain scores on the NRS. Mean handgrip force during contractions had the highest correlation coefficient (Pearson's $r=0.67$ ) compared with peak handgrip force $(\mathrm{r}=0.56)$ and area under the curve of handgrip force $(\mathrm{r}=0.55)$. CONCLUSIONS: Pain intensity and duration can be assessed continuously using handgrip force measured via a dynamometer. The feedback of intensity and duration of pain could optimize patient-controlled remifentantil application for obstetric analgesia and other situations of highly variable pain intensity.

Key Words: Analgesia; Obstetric; Patient-controlled; Remifentanil; Safety

$\mathrm{T}$ he current standard of pain assessment is rating scales such as the visual analogue scale (VAS) or the numerical rating scale (NRS). This type of evaluation has been shown to be highly effective when pain is relatively stable over a certain time frame, even for short durations, such as in postoperative pain $(1,2)$. However, for highly dynamic situations in which pain intensity can change from one minute to the next, the use of such scales is challenging and problematic because each assessment requires an interaction between the patient and the caregiver.

Examples of such dynamic situations include surgical, interventional diagnostic or therapeutic procedures. Many of these procedures are currently performed using continuous perfusions of the short-acting opioid remifentanil. Another prototypical example of dynamic pain intensity is labour. During labour, pain changes rapidly from absent to minimal pain between contractions to very intense pain during contractions.

\section{L'évaluation continue de la douleur de l'accouchement au moyen de la force de préhension}

HISTORIQUE : L'évaluation des changements dynamiques lors d'expériences douloureuses, comme l'accouchement, au moyen d'échelles d'évaluation classiques (p. ex., l'échelle d'évaluation numérique [ÉÉN]) comporte des limites. Pour remplacer l'évaluation continue de la douleur, on pourrait utiliser un signal volontaire de la parturiente. Ces mesures dynamiques de la douleur de l'accouchement pourraient être améliorées par l'administration de rémifentanil en analgésie obstétricale. Dans la présente étude, la force de préhension a été mesurée par dynamomètre pour signaler la douleur de l'accouchement.

OBJECTIFS : Évaluer si le monitorage continu de la douleur de l'accouchement par la force de préhension permet de mesurer la douleur pendant les contractions et de corréler entre la force de préhension et l'intensité de la douleur selon les scores de l'ÉÉN.

MÉTHODOLOGIE : La présente étude monocentrique d'observation incluait 43 parturientes. Une fois le dynamomètre calibré en fonction de la force musculaire de la main de la parturiente, la douleur a été enregistrée au début et à la fin de l'accouchement au moyen d'un dynamomètre et d'une ÉÉN. Le paramètre principal était le coefficient de corrélation entre les évaluations à l'ÉÉN et l'intensité de pointe enregistrée par le dynamomètre. RÉSULTATS : Toutes les lectures enregistrées par le dynamomètre l'étaient également par le tocogramme externe. Toutes les contractions enregistrées par le tocogramme externe l'étaient également par le dynamomètre. La force de préhension était modérément corrélée avec les scores de douleurs de l'ÉÉN. La force de préhension moyenne pendant les contractions présentait le coefficient de corrélation le plus élevé ( $\mathrm{r}$ de Pearson $=0,67)$ par rapport à la force de préhension de pointe $(\mathrm{r}=0,56)$ et à la surface sous la courbe de la force de préhension $(\mathrm{r}=0,55)$.

CONCLUSIONS : Il est possible de mesurer l'intensité et la durée de la douleur d'une manière continue au moyen de la force de préhension par dynamomètre. Le fait de connaître l'intensité et la durée de la douleur pourrait optimiser l'utilisation de rémifentanil contrôlé par la patiente en analgésie obstétrique et dans d'autres situations où l'intensité de la douleur est très variable.

Although epidural analgesia is currently considered to be the gold standard of analgesia during labour $(3,4)$, remifentanil patient-controlled analgesia (PCA) is increasingly used as an alternative (5-7).

To optimize remifentanil PCA for labour pain, or other uses of remifentanil PCA, a continuous feedback of pain intensity would be advantageous. In addition, during labour, a method to predict future contractions would be useful to determine the optimal moment for remifentanil bolus administration to correlate the symptom (pain) with its treatment (the peak effect of remifentanil). A continuous evaluation of pain during labour would require the possibility to construct a time series of onset and cessation of pain during contractions. This time series could be used to create a mathematical model of intercontraction intervals and to predict the occurrence of future contractions. This prediction of the onset of a future contraction may then be used to guide the application of remifentanil bolus.

${ }^{1}$ Department of Adult Intensive Care Medicine at Royal London Hospital, Barts Health NHS Trust, London, United Kingdom; ${ }^{2}$ Service

d'Anesthésiologie, Hôpitaux Universitaires de Genève et Faculté de médecine, Université de Genève, Genève 14, Switzerland

Correspondence: Dr Nadine Wickboldt, Service d'Anesthésiologie, Département APSI, Hôpitaux Universitaires de Genève, Rue Gabrielle-Perret-

Gentil 4, CH-1211 Genève 4, Switzerland. Telephone 41-223727402, fax 41-223823058, e-mail nadine.wickboldt@hcuge.ch 
The simplest way to obtain a continuous pain evaluation would be to use an electronic version of a pain scale, as previously tested in volunteers $(8,9)$. This electronic pain scale requires patients to simply use a slider or cursor to indicate their pain level. There are, however, two disadvantages of this method. First, the patient needs to concentrate continuously on the scale to position the cursor at a level corresponding to his subjective pain experience. Second, there is an inherent danger that the patient leaves the cursor in a position indicating severe pain when the pain has already subsided. When using the signal to guide for example remifentanil administration, this could be deleterious.

Therefore, we aimed to test a system which automatically resets to zero when there is no input from the patient. We tested the possibility to use handgrip force measured by a dynamometer to continuously signal pain intensity as handgrip force has been demonstrated to correlate with descriptors of pain intensity in volunteers (10).

In the present study, we investigated the use of continuous pain evaluation with the dynamometer in parturients. The objective of the study was to evaluate whether monitoring of pain during labour using handgrip force is possible and will allow assessment of pain intensity during contractions. Therefore, we compared different parameters of the pain assessment by handgrip force (peak force, mean force, duration of pain during contractions, area under the curve of force measured during a contraction) in terms of their correlation with pain assessment using a standard NRS.

\section{METHODS}

Ethics approval for the present study was provided by the Ethical Committee NAC of Geneva University Hospitals, Switzerland (HUG 12-077).

\section{Setting}

Geneva University Hospital, Switzerland, is a primary and tertiary care centre with the largest obstetrical department in Switzerland (>4000 deliveries/year).

Neuraxial analgesia (combined spinal-epidural) is commonly used by parturients $(>85 \%)$ and only a small fraction of patients benefits from a remifentanil PCA for various reasons (eg, contraindication of regional anesthesia in the presence of coagulopathies, comorbidities, anatomy or maternal wish).

\section{Study design}

The study was designed as a single-centre, observational, descriptive study. Because of its exploratory aspect, a priori sample size calculation for the present study was not possible.

Inclusion criteria were parturients $>18$ years of age, American Society of Anesthesiologists (ASA) physical status <3, ability of the participant to read and understand the information sheet and to sign and date the consent form, and status at the beginning of labour before requesting spinal-epidural analgesia. In the authors' institution, parturients are admitted to the delivery room when regular contractions are present, independent of cervical dilatation. Parturients experiencing contractions that they did not consider to be painful were included.

Exclusion criteria were patients with complicated pregnancies (preeclampsia or abnormal placentation), contraindication to neuraxial anesthesia (history of clotting disorders, septicemia, local infection at the injection site, spinal malformation) and late-stage labour with severe pain necessitating the initiation of epidural analgesia within the hour following admission.

\section{Subject recruitment and screening}

On admission to the delivery room, approximately $1 \mathrm{~h}$ before the planned beginning of the study procedure, the parturient was informed by one of the investigators about the study. Written informed consent was obtained immediately before the beginning of the study procedure by one of the investigators.

Fifty parturients were screened for the study and seven did not wish to participate.

\section{Study procedure}

Forty-three parturients were prospectively included during the period from August 2012 to November 2012. The handling of the dynamometer and use of the NRS were explained in detail to the selected parturients. To calibrate the device to individual hand muscle strength, the parturient was asked to press the dynamometer first with an intensity corresponding to moderate pain ( 5 on a NRS scale of 0 to 10 ) and then to maximal imaginable pain ( 10 on a 0 to 10 NRS), with three repetitions for each calibration measurement. Thereafter, women were instructed to compress the dynamometer with a force corresponding to their subjective pain whenever pain occurred, and hold it as long as the pain was present. Recordings were made for 20 min during the first stage of labour when women experienced regular painful contractions, but did not yet require analgesia. Alternative pain management strategies were permitted, such as relaxation techniques provided by a midwife. A second recording was taken during more advanced labour at the time when women requested epidural analgesia.

However, neither the degree of cervical dilatation nor administration of uterotonic drugs (eg, misoprostol, oxytocin) given before or during the recording nor epidural placement were limiting factors for the study. Therefore, the duration of labour before the first recording and between recordings as well as cervical dilatation were variable for each participating parturient. The maximum pain intensity during the contractions before and after epidural catheter placement and at regular time intervals thereafter were evaluated using the NRS by one of the investigators.

The dynamometer (Noraxon Biofeedback dynamometer [Velamed, Germany]) was used in combination with a portable computer to which it was connected via an analogue-digital-interface. The handgrip force (in Newtons, maximum $600 \mathrm{~N}$ ) measured by the dynamometer was recorded continuously using Signal (CED, United Kingdom). Simultaneously, the external tocographic signal of uterine contractions and an abdominal wall electromyogram were registered.

Data from the present experiment were also used in a study testing different models for the prediction of future uterine contractions (11).

\section{Analysis}

Duration of pain during the contractions was calculated as the time (in seconds) starting from the time point of baseline deviation of the dynamometer signal, indicating pain, until return to the baseline when the painful contraction was finished. The interval between contractions was measured as the time between two starting points of the deviation from baseline on the dynamometer signal.

The tracings of handgrip force were compared with the tocographic tracings to evaluate the congruence between contraction and pain. Using the Signal software, peak handgrip force, mean handgrip force and the area under the curve (AUC) of handgrip force during contractions were measured.

For each recording, parturients were asked once to evaluate subjective pain intensity. To compare the subjective pain level with the corresponding pain level obtained by handgrip force via dynamometer, the handgrip force values of all contractions in the recording sequence were averaged. Recordings with $<3$ contractions were excluded. Statistical evaluations were conducted using GraphPad Prism 4 (GraphPad, USA) and the statistical software R (12).

Pearson's correlation coefficient $r$ was used for comparison between NRS ratings and the intensity of the parameters derived from the handgrip force. $\mathrm{P}<0.05$ was considered to be statistically significant for all analyses. Normal distribution of the data was tested using the Kolmogorov-Smirnov test. Mean values are reported with their corresponding SDs.

\section{RESULTS}

The 43 participating women had a mean $( \pm$ SD) age of $32 \pm 4$ years, a mean height of $164 \pm 5 \mathrm{~cm}$ and weighed $75 \pm 11 \mathrm{~kg}$. Twenty-two of the 43 women were nulliparous, and all were singleton pregnancies 


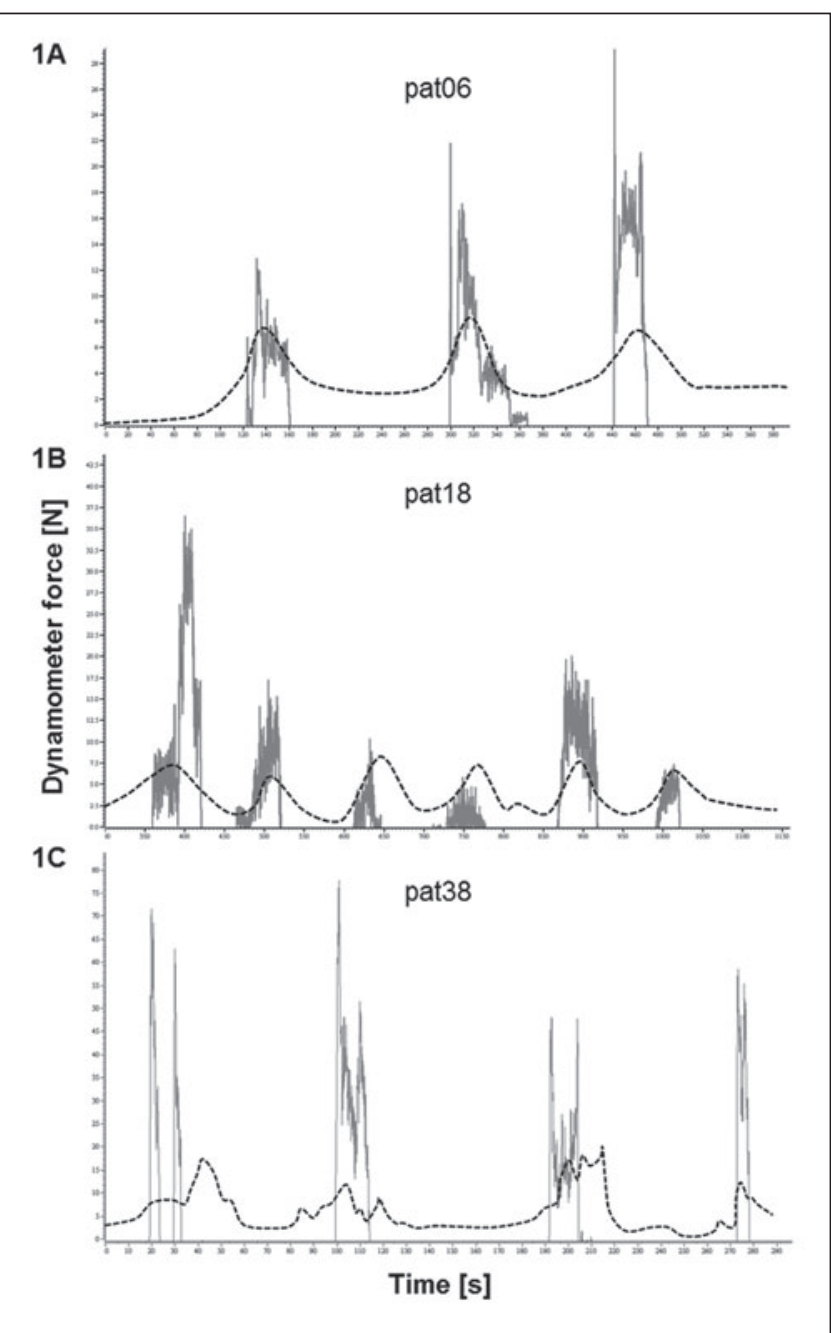

Figure 1) Original tracings of the handheld dynamometer (solid line; in N) and corresponding tocogram (dotted line) for three exemplary parturients (pat 06, 18 and 38) (1A-C)

between 37 to 42 weeks of gestation. Fourteen had received uterotonic drugs (misoprostol, oxytocin) before or during the recording. In 16 of the women, cervical dilatation was still $<20 \mathrm{~mm}$ when the second recording of pain during contractions was performed.

An example of one of the original tracings obtained via the dynamometer is presented in Figure 1. All contractions recorded by the dynamometer were also shown on the external tocogram; however, the duration of pain during the contraction was shorter (mean \pm SD $34 \pm 12 \mathrm{~s}$ ) than the corresponding time period of raised abdominal wall tension $(45 \pm 14$ s).

During the calibration procedure, when parturients were not yet experiencing pain, an imagined pain intensity of $5 / 10$ on the NRS was indicated with a mean ( \pm SD) force of $69 \pm 25 \mathrm{~N}$, and an imagined pain intensity of $10 / 10$ with a mean force of $134 \pm 35 \mathrm{~N}$. During the actual recordings, forces used by the women were actually much lower. All parturients who consented for the study and participated at the calibration procedure continued with at least one recording period.

During the first measurement before the women requested analgesia, average mean force during contractions was $19 \pm 13 \mathrm{~N}$ and mean peak force was $39 \pm 26 \mathrm{~N}$. The average pain intensity indicated on the NRS during these recordings was $5 \pm 2$ on a 0 to 10 NRS. During the second measurement, when the parturient requested epidural analgesia, average mean force during contractions was $25 \pm 13 \mathrm{~N}$ and average peak force was $48 \pm 22 \mathrm{~N}$. At this time point, the average

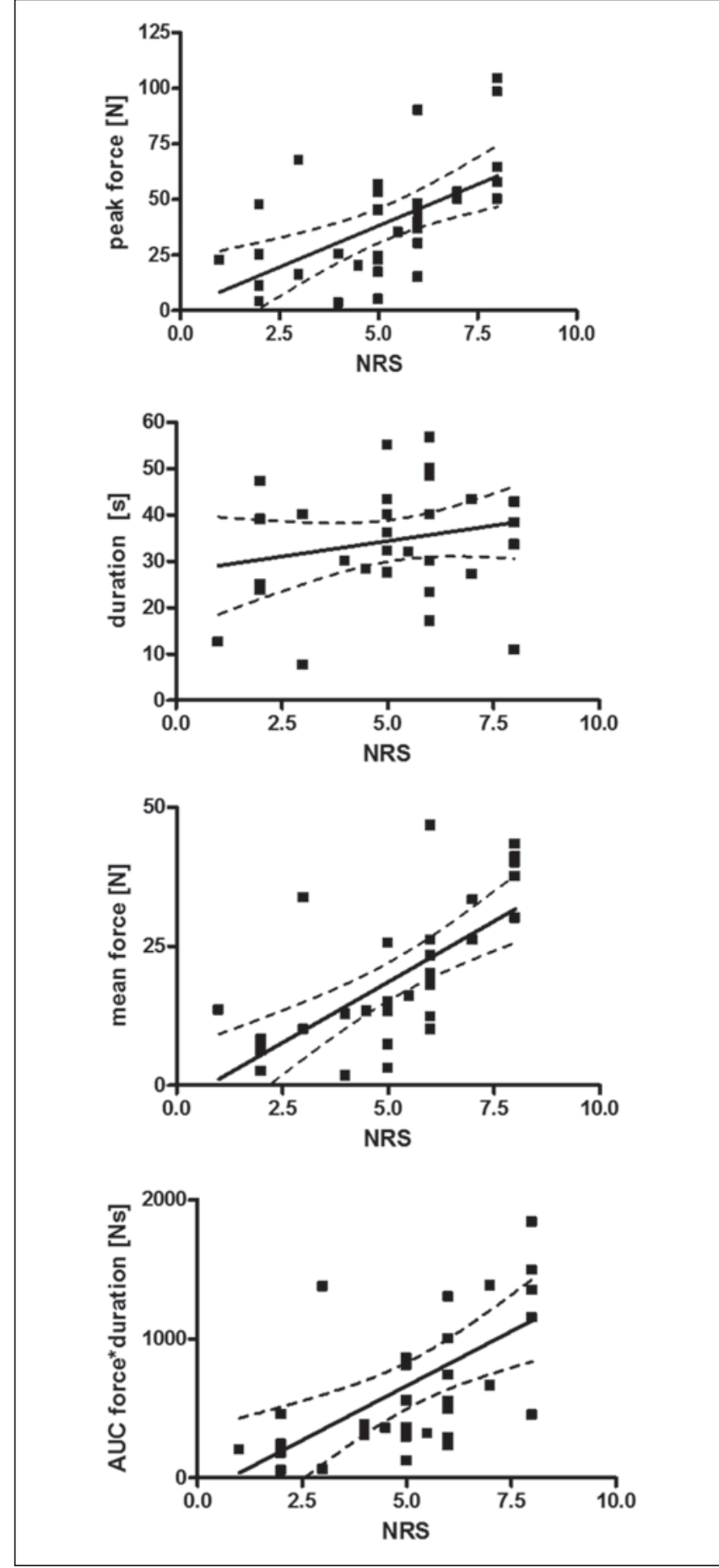

Figure 2) Correlation of peak handgrip force, duration of pain during contractions, mean handgrip force and area under the curve (AUC) of handgrip force during contractions with numerical rating scale (NRS). Points are averages of at least three contractions for each individual parturient

pain intensity indicated on the NRS scale was $7 \pm 2$. Due to the urgency of pain alleviation via epidural catheter insertion (the hospital policy requires epidural placement no later than $30 \mathrm{~min}$ after the request of the parturient), the second recording was obtained in only 24 parturients. Therefore, only data from the first recordings were analyzed further. After administration of spinal-epidural analgesia, pain intensity was reduced to approximately 0 ; therefore, handgrip force was not measured further. The correlations of the 
TABLE 1

Correlation of the handgrip force parameters with pain intensity indicated on the numerical rating scale

\begin{tabular}{lllcl}
\hline & Peak force & Duration & Mean force & \multicolumn{1}{c}{ AUC } \\
\hline $\mathrm{r}$ & 0.56 & 0.21 & 0.67 & 0.55 \\
$\mathrm{P}$ & 0.0007 & 0.2414 & $<0.0001$ & 0.0008 \\
\hline
\end{tabular}

$P<0.05$ is considered to be statistically significant. AUC Area under the curve; $r$ Pearson's correlation coefficient

handgrip force parameters with pain intensity indicated with the NRS are presented in Figure 2 and Table 1. The mean handgrip force during contractions had the highest correlation coefficient $(\mathrm{r}=0.67)$ with the NRS, followed by peak handgrip force $(r=0.56)$. The AUC of handgrip force during contractions had a correlation coefficient of $r=0.55$, whereas duration of pain during contractions was not significantly correlated with pain indicated on the NRS. Due to the small number of data point differences between the correlation coefficients, there were no statistically significant differences except between the correlation coefficients of mean force and duration (exploratory analysis without prior power calculation, Williams modification of the Hotelling test, $\mathrm{P}=0.05$ ) (13).

\section{DISCUSSION}

The present study demonstrated the practice ability of using handgrip force to continuously assess pain intensity during labour pain, which fluctuates dramatically during contractions, with low or no pain in between contractions, and high pain intensity during contractions. Gracely et al (10) observed that time duration and handgrip force responses to a stimulus correlated highly with responses on ratio scales of sensory and affective verbal pain descriptors derived from numerical magnitude estimation respectively.

In the present study, mean handgrip force, rather than the AUC of handgrip force or peak force, was found to be the parameter that correlated best with pain intensity indicated on standard NRS. It should be noted that differences between correlation coefficients need to be confirmed by a study with prior power calculation.

The correlation of handgrip force recorded by the dynamometer with subjective pain level expressed on the NRS was not sufficient to infer a subjective pain level from a particular force value, but it was sufficient to assess whether pain is present - ie, to indicate the painful time during a contraction. In future studies, whether the variability in the correlation between NRS and handgrip force arises from interindividual differences or intraindividual variability should be investigated.

Understanding of the use of the device may be different in patients from different socioeconomic or cultural backgrounds. The sample size in the present study was too small to analyze differences between such subgroups; this should be evaluated in follow-up studies. Our study did not include feedback from the parturients concerning the usability of the device. Such data are needed to evaluate the feasibility of using the dynamometer in clinical practice.

This dynamometer method is potentially appropriate for the guidance of remifentantil administration during labour because pain peak during contractions was identified as at least a moderate correlation $(r>0.5)$ between pain measured via NRS and via handgrip force recorded by the dynamometer.

When pain became sufficiently intense to request epidural analgesia, some of the parturients did not wish to continue to press the dynamometer. This may be related to fatigue or due to lack of parturient motivation with no incentive to continue. However, during the recording periods, no signs of fatigue (diminishing handgrip force) were present. It may be interesting to perform a similar study in a centre in which at least some parturients deliver without neuraxial anesthesia ( $<15 \%$ of births in Geneva, Switzerland) to evaluate the correlation of handgrip force with the NRS for intense pain. Furthermore, once handgrip measurement is related to prediction of contractions and to calculation of the optimal time point of remifentanil bolus application, future studies should investigate whether an increase in compliance occurs. Here, measurement will directly be related to pain treatment and the latter will serve as an incentive.

We observed that the participants may have sometimes pressed the dynamometer according to pain intensity only at the beginning of a contraction, instead of continuing to apply a corresponding force until the pain has subsided (Figure 1A and 1C). It is not possible from our data to judge whether this is due to a true decrease in pain intensity during an ongoing contraction or due to fatigue when pressing the dynamometer. In any case, we were able to measure duration of pain because the dynamometer was always pressed until the end of each contraction, although with diminishing force. During the calibration procedure, women were able to sustain pressure for prolonged periods without fatigue.

The beginning of pain during contractions can be determined precisely using the dynamometer recordings. This information could be used to calculate time series of painful contractions, which then could be used to predict future contractions by creating a statistical model of intercontraction intervals. Forecasting the occurrence of a future contraction may allow optimization of remifentanil bolus application to treat labour pain. Currently, a remifentanil bolus is only applied when a contraction is felt by the parturient. Using this method, remifentanil arrives too late to alleviate pain at the beginning of the contraction. Using contraction forecasting based on a time series of previous contractions, it may be possible to deliver the remifentanil bolus before the start of the contraction, optimizing the coincidence of pain and remifentanil concentration. Although handgrip force remains a subjective measure, unlike external tocography, the signal of the latter is too unreliable to be used to create time series of contractions. Recently, the signal of an intrauterine pressure catheter has been successfully used to predict uterine contractions (14). However, such a device is invasive and can, thus, rarely be used in clinical practice. An alternative may be a signal generated by voluntary action of the parturient, such as the dynamometer signal tested in this study.

Several studies have demonstrated the safe application of patient-controlled remifentanil during labour, which is superior to a continuous infusion (15) and a good alternative to neuraxial analgesia in the presence of contraindication for neuraxial blockage $(16,17)$ or of maternal wish $(18)$. The use of remifentanil, although not uniformly supported by all available evidence, has become more popular in the recent years, and in some institutions it is even routinely used $(5,19,20)$. However, its potential as a potent $\mu$-agonist to provoke adverse effects, as reported recently, must be kept in mind $(21,22)$. Therefore, it is important to adapt remifentanil dose and bolus timing to patient's need. This could be achieved by a method to predict future contractions to adjust remifentanil bolus application, and by adjusting bolus dose to pain intensity. Feedback of the dynamometer signal to a remifentanil PCA pump may be a way to improve efficacy and safety of remifentanil dosing.

\section{SUMMARY}

The present study demonstrated that labour pain may be assessed using handgrip force measured via a dynamometer. Further studies are needed to investigate whether this technique may be used to guide remifentanil titration in situations of very dynamic pain intensity such as labour pain.

ACKNOWLEDGEMENTS: The authors thank all participating parturients and midwives for their support of the study. The authors are grateful to Julian Klug (Geneva University) for help with the statistical analysis.

DISCLOSURES: This study was supported by departmental funds of the Department of Anesthesiology, Pharmacology and Intensive Care of the University Hospitals of Geneva. The authors do not have any other financial support or sponsorship, or other conflicts of interest to declare. 


\section{REFERENCES}

1. Jensen MP. Measurement of pain. In: Fishman SM, Ballantyne JC, Rathmell JP, eds. Bonica's management of pain, 4 th edn. Media, Philadelphia: Lippencott Williams \& Wilkins, 2010:251-70.

2. Turk DC, Melzack R. Handbook of pain assessment. New York: The Guilford Press, 1992.

3. COG: Pain Relief During Labor. ACOG Committee on Obstetric Practice 2004, Number 295.

4. Gogarten W, Van Aken H, Kessler P. Durchführung von Analgesie- und Anästhesieverfahren in der Geburtshilfe. Anästh Intensivmed 2009;50:502-7.

5. Kranke P, Girard T, Lavand'homme P, et al. Must we press on until a young mother dies? Remifentanil patient controlled analgesia in labour may not be suited as a "poor man's epidural".

BMC Pregnancy Childbirth 2013;13:139.

6. Hughes D, Hodgkinson P. Remifentanil PCA for labour analgesia. Anaesthesia 2013;68:298.

7. Schnabel A, Hahn N, Broscheit J, et al. Remifentanil for labour analgesia: A meta-analysis of randomised controlled trials. Eur J Anaesthesiol 2012;29:177-85.

8. Boormans EM, van Kesteren PJ, Perez RS, Brolmann HA, Zuurmond WW. Reliability of a continuous pain score meter: Real time pain measurement. Pain Pract 2009;9:100-4.

9. van Wijk AJ, Lobbezoo F, Hoogstraten J. Reliability and validity of a continuous pain registration procedure. Eur J Pain 2013;17:394-401.

10. Gracely RH, McGrath F, Dubner R. Ratio scales of sensory and affective verbal pain descriptors. Pain 1978;5:5-18.

11. Rehberg B, Wickboldt N, Juillet C, Savoldelli G. Can remifentanil use in obstetrics be improved by optimal PCA bolus timing? Br J Anaesth 2015;114:281-9.

12. R Development Core Team. R: A language and environment for statistical computing. R Foundation for Statistical Computing. Vienna, Austria; 2008. <www.R-project.org> (Accessed July 15, 2012).
13. Kenny D. Testing measures of association. In: Kenny D, ed. Statistics for the social and behavioral sciences. United States of America: Libary of Congress Cataloging-in-Publication Data, 1987:270-91.

14. Huang Z, Shyu ML, Tien JM, Vigoda MM, Birnbach DJ. Prediction of uterine contractions using knowledge-assisted sequential pattern analysis. IEEE Trans Biomed Eng 2013;60:1290-7.

15. Shen MK, Wu ZF, Zhu AB, et al. Remifentanil for labour analgesia: A double-blinded, randomised controlled trial of maternal and neonatal effects of patient-controlled analgesia versus continuous infusion. Anaesthesia 2013;68:236-44.

16. Jones R, Pegrum A, Stacey RG. Patient-controlled analgesia using remifentanil in the parturient with thrombocytopaenia. Anaesthesia 1999;54:461-5.

17. Thurlow JA, Waterhouse P. Patient-controlled analgesia in labour using remifentanil in two parturients with platelet abnormalities. Br J Anaesth 2000;84:411-3.

18. Roelants F, De Franceschi E, Veyckemans F, Lavand'homme P. Patient-controlled intravenous analgesia using remifentanil in the parturient. Can J Anaesth 2001;48:175-8.

19. Hill D. Remifentanil patient-controlled analgesia should be routinely available for use in labour. Int J Obstet Anesth 2008;17:336-9.

20. Lavand'homme P, Roelants F. Patient-controlled intravenous analgesia as an alternative to epidural analgesia during labor: Questioning the use of the short-acting opioid remifentanil. Survey in the French part of Belgium (Wallonia and Brussels). Acta Anaesthesiol Belg 2009;60:75-82.

21. Pruefer C, Bewlay A. Respiratory arrest with remifentanil patientcontrolled analgesia - another case. Anaesthesia 2012;67:1044-5.

22. Bonner JC, McClymont W. Respiratory arrest in an obstetric patient using remifentanil patient-controlled analgesia. Anaesthesia 2012;67:538-40. 


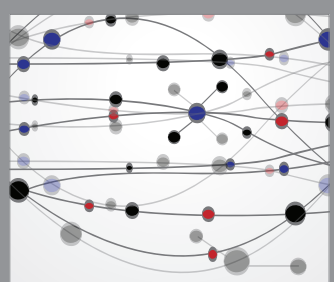

The Scientific World Journal
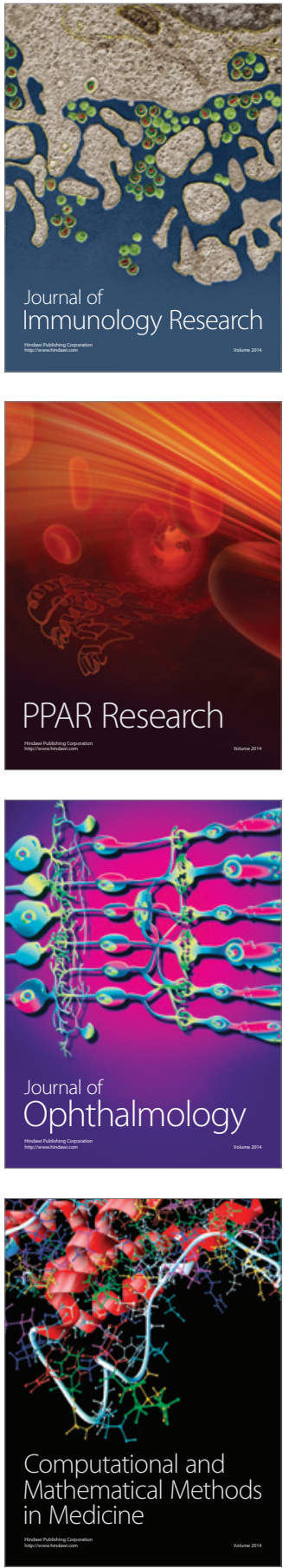

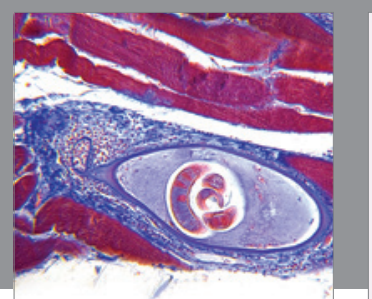

Gastroenterology Research and Practice

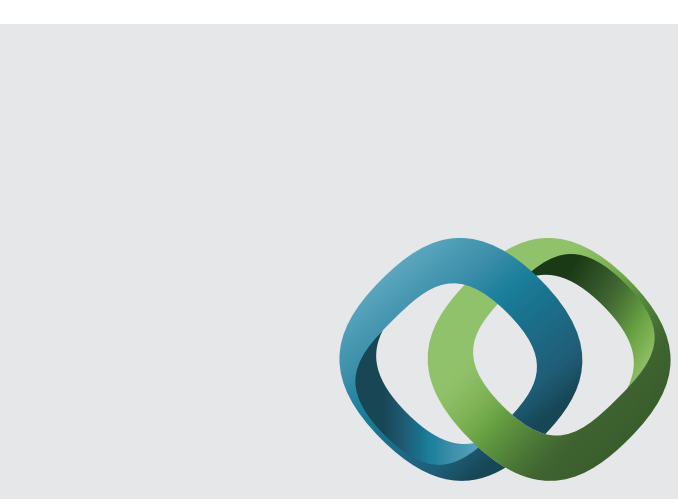

\section{Hindawi}

Submit your manuscripts at

http://www.hindawi.com
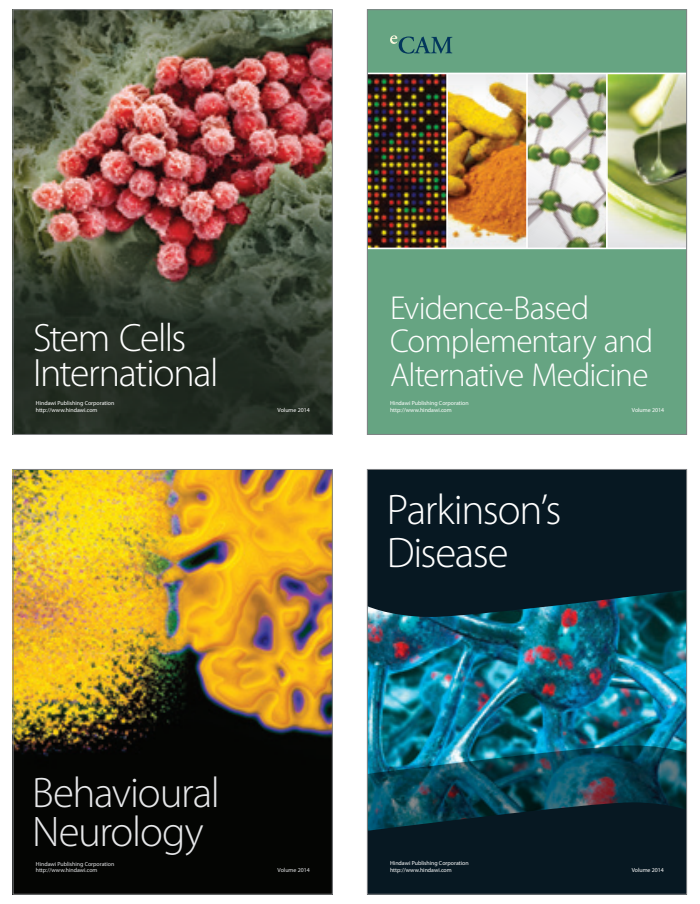
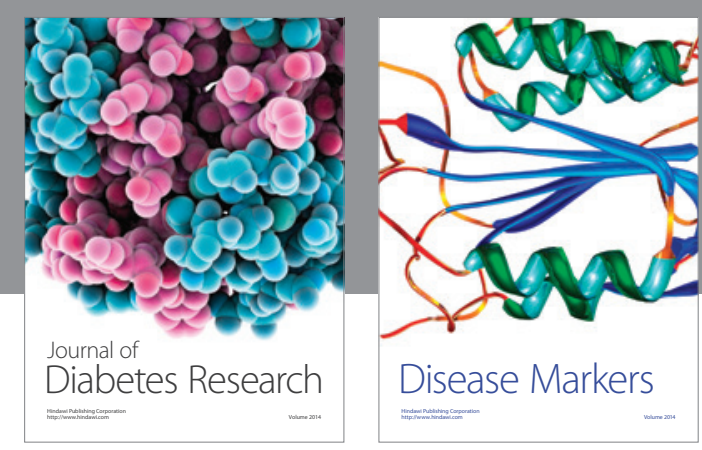

Disease Markers
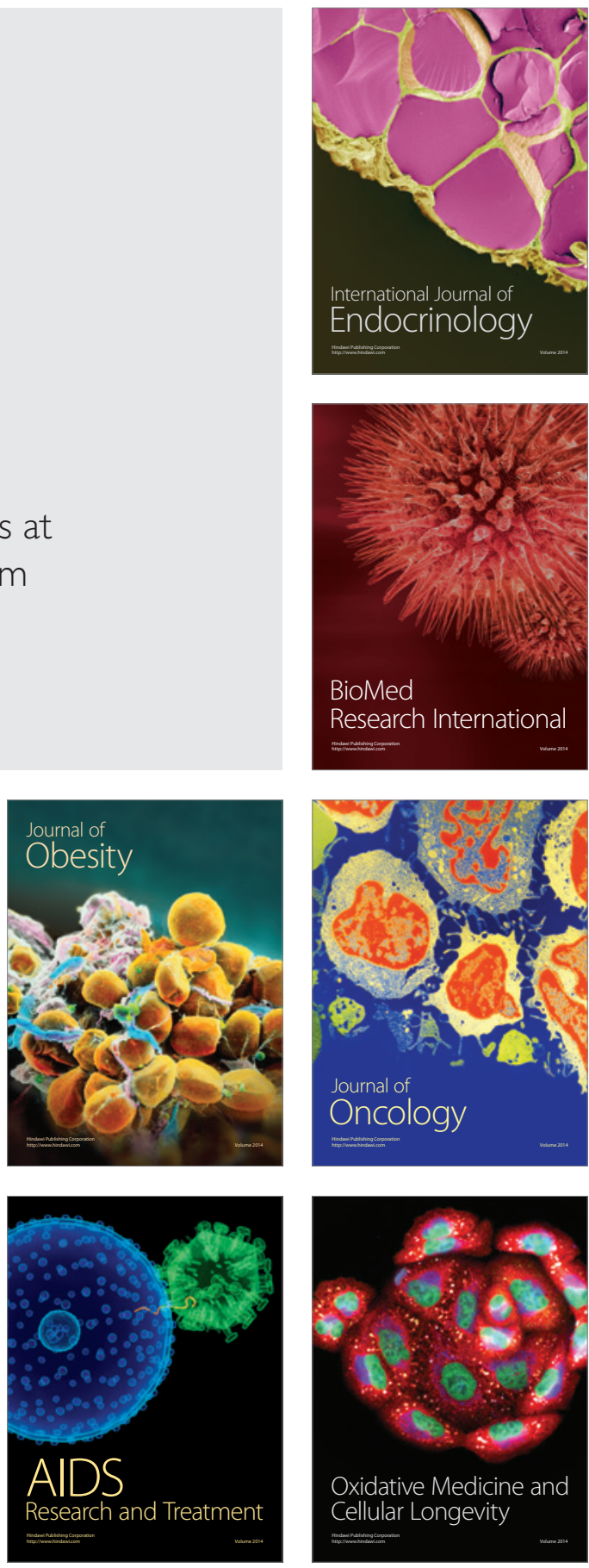